\title{
Innovations in environmental bioprocesses for sustainable development
}

\author{
Eldon R. Rene ${ }^{1} \cdot$ Thallada Bhaskar $^{2} \cdot$ Byoung-In Sang $^{3} \cdot$ Samir Kumar Khanal $^{4} \cdot$ Ashok Pandey $^{5}$ \\ Published online: 29 April 2020 \\ (C) Springer-Verlag GmbH Germany, part of Springer Nature 2020
}

The rapid growth of population, urbanization and climate change is causing serious threat to the future of human societies and the ecosystem. Technological innovation is the function through which new technologies are introduced into the society. In this line of progressive research, the special issue contains 26 articles selected from the "Biotechnological Research and Innovation for Sustainable Development" (BioSD-2018) conference that was held during November 22-25, 2018, at the CSIR-Indian Institute for Chemical Technology (IICT), Hyderabad, and the "Bio-Innovation for Environmental and Health Sustainable Developments" (BEHSD-2018) held from November 27-28, 2018, at the CSIR-Indian Institute of Toxicology Research, Lucknow. These two conferences were conducted in association with The Biotech Research Society, India (BRSI) and the International Bioprocessing Association - An International Forum on Industrial Bioprocesses (IBA-IFIBiop). These conferences focused the advancement of research and innovations on interdisciplinary topics in the domains of health, environment, food, water and energy which have been highly pertinent to realize sustainable development goals. The conference also aimed to address the current challenges in creating a sustainable and affordable ecosystem in the framework of cutting edge $R \& D$ interventions. A total of $\sim 1000$ participants attended both the conferences from all over the world.

The special issue covers the various advancement of research and innovations in the field of environmental biotechnology, particularly for resource recovery of waste and the treatment of liquid and solid wastes. These fields are highly pertinent to realize the sustainable development goals. The guest editors of this special issue are thankful to the Editor-in-Chief of Environmental Science and Pollution Research (ESPR), Professor Philippe Garrigues, for providing an opportunity to publish selected peer-reviewed papers that were presented at BioSD-2018 and BEHSD-2018. Our special thanks to Ms. Fanny Creusot and Ms. Florence Delavaud, Editorial Assistants of ESPR, and the entire production team at Springer for their valuable support in bringing out this issue successfully. We also thank all the reviewers for providing critical reviews, comments and feedback on manuscripts that were submitted for this thematic special issue. We firmly believe that you will enjoy reading the manuscripts presented in this special issue and also share the issue with your research colleagues.

Responsible editor: Philippe Garrigues

Eldon R. Rene

e.raj@un-ihe.org

Thallada Bhaskar

thalladab@yahoo.com

Byoung-In Sang

biosang@gmail.com

Samir Kumar Khanal

khanal@hawaii.edu

Ashok Pandey

ashok.pandey1@iitr.res.in
IHE Delft Institute for Water Education, Westvest 7, 2611AX Delft, The Netherlands

2 Material Resource Efficiency Division (MRED), Biomass Conversion Area (BCA), CSIR-Indian Institute of Petroleum (IIP), Dehradun 248005, India

3 Department of Chemical Engineering, Hanyang University, 222 Wangsimni-ro, Seongdong-gu, Seoul 04763, Republic of Korea

4 Department of Molecular Biosciences and Bioengineering, University of Hawai'I at Manoa, Honolulu, HI, USA

5 Centre for Innovation and Translational Research, CSIR-Indian Institute of Toxicology Research, Lucknow 226001, India 


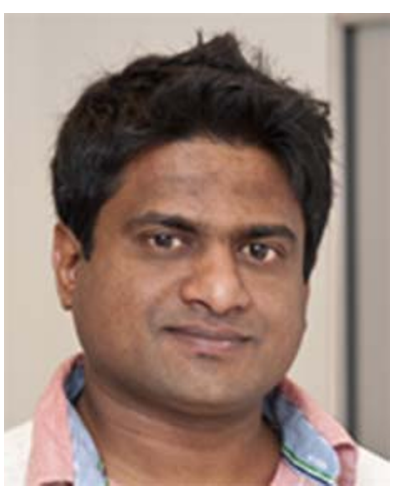

Eldon R. Rene is currently working as a Senior Lecturer at IHE Delft, Institute for Water Education, The Netherlands. He obtained his University Teaching Qualification (UTQ) diploma from IHE Delft and a PhD in Chemical Engineering from the Indian Institute of Technology Madras (India). Eldon's broad research interests are related to the development of biological treatment processes for wastewater and waste gas treatment, resource recovery and the use of artificial intelligence tools for environmental monitoring and environmental process control. He has published three books, 225 papers, $~ 50$ book chapters and seven monographs. He is an Associate and Review Editor of the Journal of Environmental Engineering, editorial board member of Bioresource Technology Reports, Review Editor of Frontiers in Energy Research and Associate Editor of Environmental Quality and Management. As a part of his educational and capacity building efforts, Eldon has taught scientific writing and skill development to $23000 \mathrm{MS}$ and $\mathrm{PhD}$ students in major international events or workshops held in 28 countries.

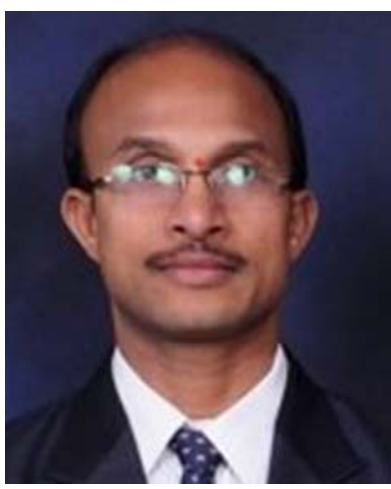

Dr. Thallada Bhaskar, FRSC, FBRS, FTAS, FISEES, FIBA, Senior Principal Scientist, is currently heading the Material Resource Efficiency Division (MRED) at the CSIR-Indian Institute of Petroleum, Dehradun, India. He carried out postdoctoral research and worked as an Assistant Professor at the Okayama University, Okayama, Japan. His research experience and expertise is in heterogeneous catalysis, thermo-chemical conversion of biomass, waste plastics and e-waste (WEEE) into value-added hydrocarbons and hydrotreatment of fossil-based crudes, etc. He has 150 publications with $h$-index of 45 and around 6050 citations, 32 book chapters and 14 patents. He is on the editorial board of five international journals and editor for six books. He has received several prestigious awards from AIST (2013), Japan; FSRJ, Japan (2008); CAS, China (2016); JSPS Visiting Scientist (2009); Visiting Scientist at SINTEF, Norway (2013); and Raman Research Fellowship (2013)

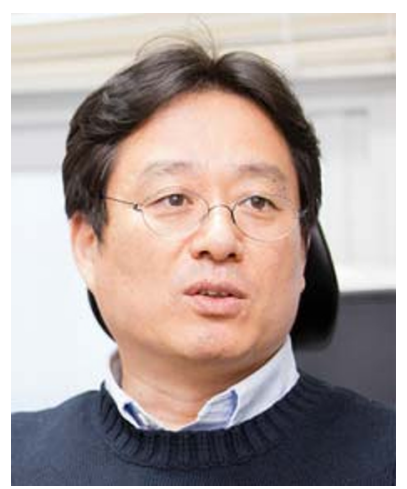

Dr. Byoung-In Sang is a Professor of Chemical Engineering, at Hanyang University, Seoul, Korea. Dr. Byoung-In Sang is currently the Director of Environment \& Health Graduate Program and Department Chair of Chemical Engineering, at Hanyang University, Seoul, Korea. He obtained his Ph.D. at Tokyo Institute of Technology, Japan, in 2001 and a postdoctoral Research Fellowship at Northwestern University, USA, during 20012003. He joined the Korea Institute of Science and Technology in February 2003 as a Senior Research Scientist and became a Principal Research Scientist in March 2008. During 2014-2016, Dr. Sang worked as the Program Director of Bio- and Waste Energy R\&D Program for Ministry of Trade, Industry, and Energy, Korea. From 2017, he has been a Committee Member of the Presidential Advisory Council on Science and Technology, Korea. His research and publication in the area of Industrial and Environmental Biotechnology have produced $>10$ international patents, $>50$ domestic patents and $>120$ peer-reviewed papers with $>3300$ citations and $h$-index 29. He is an associate editor of the Water-Energy Nexus.

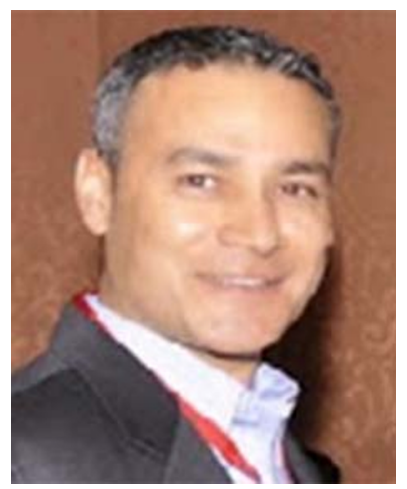

Dr. Samir Kumar Khanal is a Professor of Environmental Engineering in the Department of Molecular Biosciences and Bioengineering, University of Hawai'i at Mānoa (UHM) and Leading Professor at China Agricultural University, Suzhou, China. Dr. Khanal obtained his $\mathrm{PhD}$ in Civil Engineering with a focus in Environmental Biotechnology from the Hong Kong University of Science and Technology (HKUST), Hong Kong, in 2002 and M.S. in Environmental Engineering from the Asian Institute of Technology (AIT), Bangkok, Thailand, in 1997. Dr. Khanal was a postdoctoral research associate and Research Assistant Professor in the Department of Civil, Construction and Environmental Engineering at the Iowa State University. Dr. Khanal's research focuses on anaerobic digestion, bioenergy, waste-to-resources, nanobubble technology and environmental biotechnology. Dr. Khanal is an Associate Editor of Bioresource Technology. Dr. Khanal was the recipient of Board of Regent's Medal for Excellence in Research (2018) and CTAHR Dean's Award for Excellence in Research (2016). Dr. Khanal is a professional engineer in the State of Iowa. 


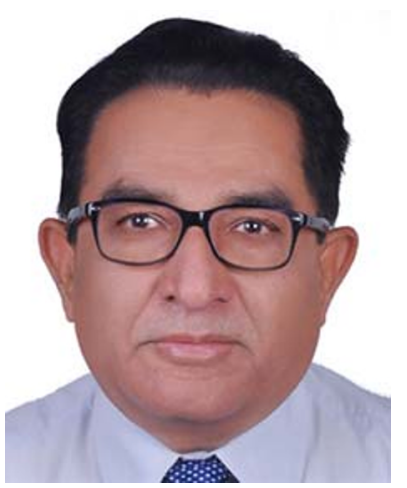

Professor Ashok Pandey is currently a distinguished scientist at the Centre for Innovation and Translational Research, CSIRIndian Institute of Toxicology Research, Lucknow, India, and the Executive Director (Honorary) at the Centre for Energy and Environmental Sustainability, Lucknow, India. His major research and technological development interests are industrial and environmental biotechnology and energy biosciences, focusing on biomass to biofuels and chemicals, waste to wealth and energy, industrial enzymes, etc. Professor Pandey is an Adjunct/Visiting Professor/Scientist in universities in France, Brazil, Canada, China, Korea, South Africa, Switzerland, and also in several universities in India. He has $\sim 1375$ publications/communications, which include 16 patents, 83 books, 700 papers and book chapters, etc. with $h$-index of 97 and $>43,000$ citations (Google scholar). Professor Pandey is the recipient of many national and international awards and honours, which include the Highest Cited Researcher (Top $1 \%$ in the world; Top 10 in India), Clarivate Analytics, Web of Science (2019); Yonsei Outstanding Scholar, Yonsei University, Seoul, Korea (2019); Highest Cited
Researcher (Top 1\% in the world; Top 10 in India), Clarivate Analytics, Web of Science (2018); Life-Time Achievement Award from the Biotech Research Society, India (2018); Life-Time Achievement Award from Venus International Research Awards (2018), Most Outstanding Researcher Award from Career360 (2018); Life-Time Achievement Award from the International Society for Energy, Environment and Sustainability (2017); Academician of European Academy of Sciences and Arts, Austria (2015); Honorary Doctorate degree from Univesite Blaise Pascal, France (2007); Thomson Scientific India Citation Laureate Award, USA (2006); UNESCO Professor (2000), etc. He is fellow of various academies, which include Royal Society of Biology, UK (2016); International Society for Energy, Environment and Sustainability (2016); National Academy of Sciences, India (2012); Association of Microbiologists of India (2008); International Organization of Biotechnology and Bioengineering (2007); and the Biotech Research Society, India (2005). Professor Pandey is the Editorin-chief of Bioresource Technology (http://ees.elsevier.com/bite/), Honorary Executive Advisor of Journal of Energy and Environmental Sustainability (www.jees.in) and Subject Editor of Proceedings of National Academy of Sciences, India (https://www.springer.com/life+ sciences/journal/40011). 